\title{
Sustainability versus urbanism: a fear-formed impasse
}

\author{
J. Callender \\ School of Architecture, Mississippi State University, USA
}

\begin{abstract}
The current interest in sustainability has created difficulties for those attempting to rethink issues of urban form. Most challenging is the lack of consensus on what is meant by a sustainable city. At first glance, this lack of consensus could be pinned on our inability to define sustainability or to clarify the motives that have spawned its remarkable rise. We intend to argue, however, that it is not a failure of lexicon, but the fact that implicit definitions of, and seldom-articulated motives for, sustainability are contrary to our notions of urban life.

When addressing sustainable issues, international design journals frequently highlight single-family, detached housing using advanced technologies, recycled and recyclable materials, and passive strategies as models. In America, LEED checklists and the annual Solar Decathlon reinforce this nascent impression that sustainability is first and foremost a matter of technological advance, which does not necessitate a corresponding rethinking of land use, density or urban form. Even when second and third looks reveal the deeper importance of land use planning and life cycle analysis, seldom is perception of form broached. The experiential appears outmoded in the face of such dire concerns.

This paper will relocate perceptual concerns to the forefront of developing a sustainable city in two ways. Firstly, utilizing frameworks provided by Henri Lefebvre and Doreen Massey, we will argue the primacy of the city in fostering sustainable ways of life through proper land use, density, and consolidation of resources. Secondly, turning to Hegel, Merleau-Ponty, and Judith Butler, I will argue that the creation of a phenomenal city - a city rooted in the bodily experience of desire - is the necessary trigger to spur human migration to technologically sustainable cities.
\end{abstract}

Keywords: sustainability, urban issues, phenomenology, desire, density. 


\section{Introduction: discrepancies of meaning}

The orthodoxy of words is damning. What, for instance, does the phrase 'to sustain' mean to the bulk of English language users? Answers to this question cluster around the phrase 'to not change'. At root, there is some truth in this construct: obviously there is something we are attempting to maintain through the lens of sustainability but what that something is is not inherent in the term itself. Attempts to define that something have led to a proliferation of sustainabilities from the maintenance of maximum bio-diversity (the position of B. McKibben, E.O. Wilson, and others) to maintenance of our current human way of life (the apparent position of many planners, architects, and laymen) to maintenance of natural resources - that is, in practical terms, maintenance of access to energy (the chief concern of politicians).

Arguing for one or another among these sustainabilities is not the intent of this paper. At issue is the relative inability of these various constructs - all, at root, fashioned upon a resistance to change - to serve urban forms that are changing and, arguably, must change in order to be sustainable. That is to say, any call for 'a sustainable city' that implicitly understands this to be 'an unchanging city' will be unable to address the fact that cities are likely to be home to $75 \%$ of the world's population by 2050 (Burdett and Sudjic [1]). So, how do we construe sustainability in relation to cities? This question lingers.

The discrepancy between sustainability as unchanging and sustainability as preparing for the future is only one of the difficulties faced in conceptualizing a sustainable city, and not the most significant. Instead, I will argue, the positing of a sustainable city of and for the future founders on the synergistic convergence of three factors: an implicit association of sustainability with nature and rural systems of development, faith in the power of technology to solve every problem, and a fear of cities.

\section{Fear and technology in the American small town}

If words are damning, how much more so are images? From time to time (and in growing frequency in the United States, it seems) design journals feature singlefamily, detached housing incorporating recycled and recyclable materials, passive strategies, and advanced technologies as visual models for successful sustainable design. Auburn University's Rural Studio in Newbern, Alabama is frequently touted as an example utilizing several of these strategies: recycled, recyclable, and passive, fig. 1. As the name of the program suggests, however, the work is intentionally and overtly rural, one home per large open natural space. On the other hand, the annual US government-sponsored Solar Decathlon (a competition of American universities to design and build energy efficient single family homes) highlights an interesting array of 'sustainable' technologies. Again, as with the work of the Rural Studio, issues of land use planning, density, and urban form are absent in favour of suburban and ostensibly self-contained solutions to the problem of diminishing natural resources. 


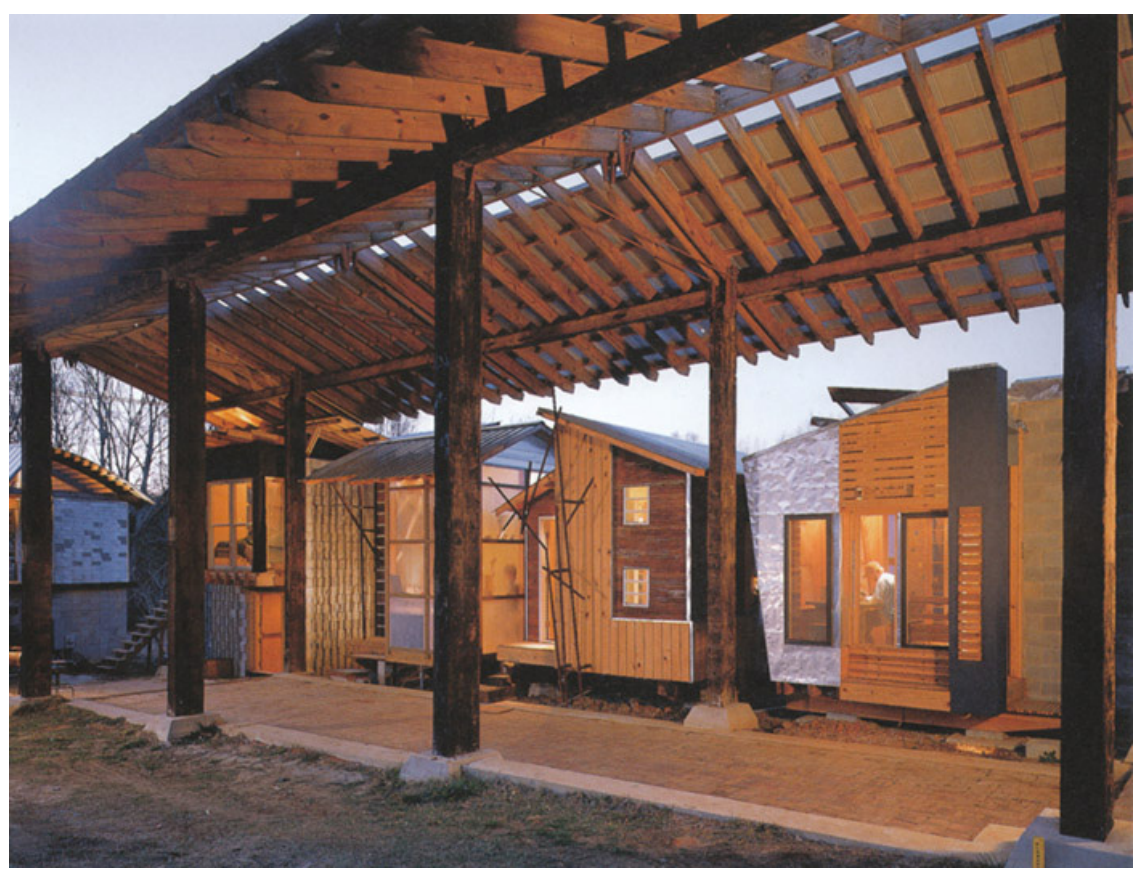

Figure 1: 'Supershed’ Auburn Rural Studio, Auburn, AL, USA.

These powerful visual assertions combined with new LEED rating legislation - mandating technologies and rewarding 'green' amenities - foster and legitimize the nascent impression that sustainability is first and foremost a matter of technological advance that is independent of local, regional, and global contextual concerns. In turn, acre upon acre of some the richest farmland in the world is compacted under the suburban sprawl of the American Midwest without much attention given to the question of what we are trying to maintain or who 'we' are.

Significantly, the unspoken nature of socio-cultural identity - the absence of thought about who 'we' are - is an outcome of the exaggerated horizontal distancing that rural and suburban planning strategies produce. Americans' fear of other people, people unavoidable in cities, noted by S. Body-Gendrot [1] and others [2], is allowed to operate quietly under the auspices of a citizenly duty to technology and the assumed wholesomeness of nature. One has only to map the land area required to house the population of a large world city (Tokyo) at the density of an average American town (Jackson, MS), however, to see the shortsightedness and utter unsustainability of this inattention to land planning and density, fig. 2 .

Fear - of cities, of climatological catastrophe - turns us toward 'practical' solutions. Even when deeper analyses of sustainability and the environment are performed and the importance of land use planning, life cycle analysis, and local, regional, and global economies are clearly understood - e.g. analyses provided 
by Edward O. Wilson [3] and Bill McKibben [4] - seldom is fear sufficiently overcome to allow for an exploration of those things we might truly want to maintain: experiences of joy and desire, for example. Less frequently, if ever, is perception of form broached as related to these richer, more sustaining experiences. Understandably, experiential concerns appear outmoded or, at best, trivial in the face of such dire concerns. And yet, ironically, without the development of alluring cities (maximizing the character and quality of human life) which draw people together in dense inhabitation and simultaneously allow for the preservation of vast natural habits (maximizing bio-diversity) and minimize the use of natural resources for construction, heating, cooling, transportation (energy), there will be nothing to sustain. The world will be a mass of near continuous but underutilized development incapable of supporting large life forms - whether plant, human or other animal [3].

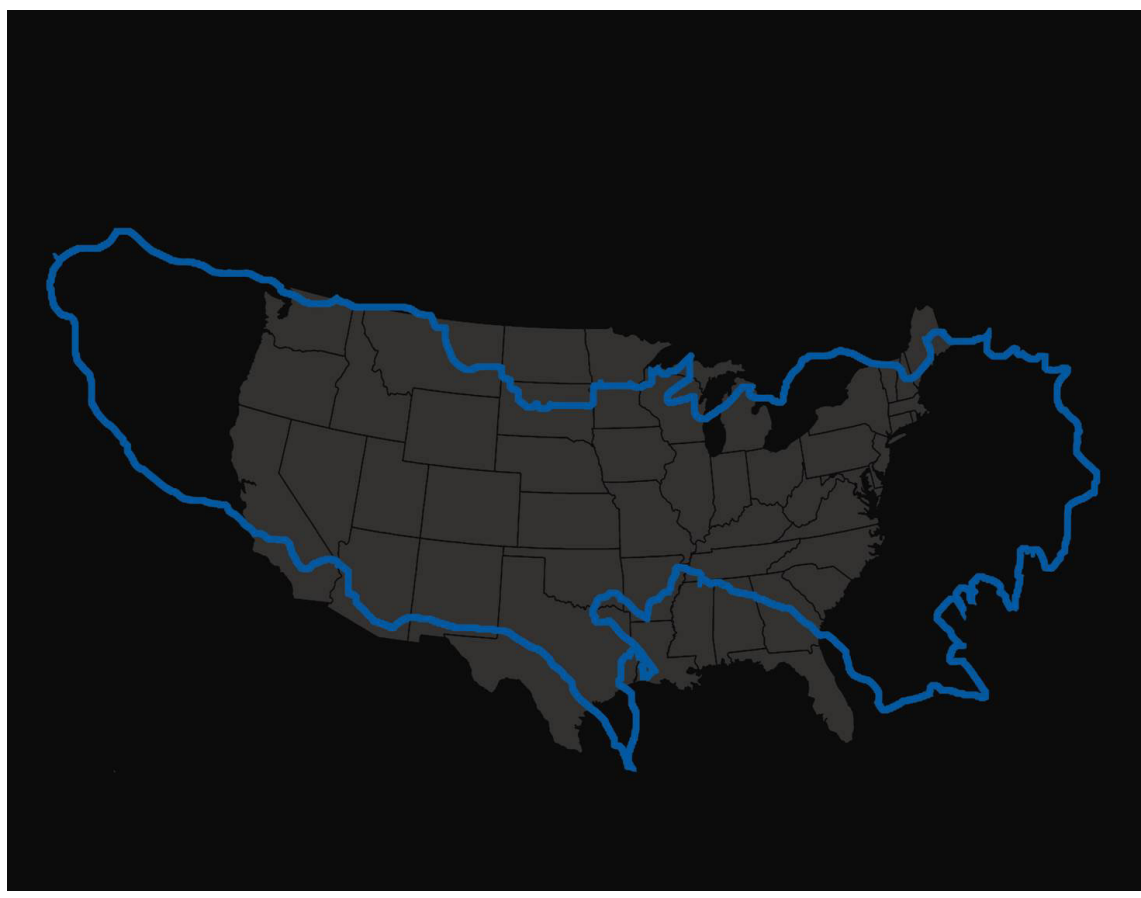

Figure 2: The size of the city of Tokyo compared to the United States if the population density of Tokyo was reduced to that of Jackson, Mississippi, USA.

\section{The sustainable city}

Words and images are damning; fear is paralyzing. In fear, people become riskaversive. Unfortunately, in the minds of most, the mapping of activities according to inherent risk directly corresponds to the activities' quantifiable 
benefits; measurable benefits equal low risk; qualitative, non-quantifiable benefits equal high risk, equals fear, equals inaction. The benefits of living in a city relative to living a sustainable life are unclear to most. This suggestion implies risk. That the sustainable city is a necessary part of sustainability broadly conceived is easy to say; the problem is that the quantitative benefits of living in a city are largely residual. First and last, people must be drawn to cities and encouraged to remain on the basis of quality of experience. This immeasurable aspect is primary.

\section{1 'Nature' homogenizes}

"Ideologically, technically, and politically, the quantitative has become the rule, norm, and value. How can we escape the quantifiable?" This question was first framed in relation to urbanism by Henri Lefebvre in 1970 [5]. A second, related question follows: what do we do in the absence of the quantifiable? It seems that, in lieu of quantities and in avoidance of resorting to qualities, people turn to tautologies and easy correspondences: 'to sustain' means 'to not change'; sustainability is a privileging of nature and maintenance of 'natural' ways of life; etc. Evidence of both this resistance to change and the implicit valuing of nature over the manmade and, in particular, over cities was documented by Lefebvre: "Theoretically, nature is shrinking, but the signs of nature and the natural are multiplying, replacing and supplanting real 'nature' [5]." But what do these correspondences, assumptions, and reactions - grasped for clarity, for immediate action, and in order to allay fears - entail for the city? There are many possible answers to this question. Anecdotally, the most apparent outcome is dispersal. That is to say, the replication of nature in the city leads to its counter-productive, non-sustainable horizontal attenuation (see figs. 2 and 3).

Dispersal, again, is just the most obvious result, and possibly not the most insidious. At a deeper level, there is a real danger that these correspondences, assumptions, and reactions overtime lose the appearance of mere provisional tools and slowly acquire the appearance of solidity and 'truth' generally reserved for natural facts. It is possible that a belief in the orthodoxy of 'real nature' is a far more difficult and deeply entrenched problem insofar as, in the hands of developers offering to bring real nature to the poor city dweller, this construct lends legitimizing force to the activity of dispersal.

Yet this legitimizing discourse is residue of a hollow tradition. Geographer and theorist Doreen Massey argues convincingly that nature does not exist in any pre-given, essential or 'natural' sense [6]. Speculatively I would add that the city and nature are similar and mutually supporting constructs; without one the other would lose all meaning. It is in this sense that dispersal does its greatest harm. Mimetic efforts to 'green' cities blur both the constructs of city and nature; it empties both of meaning; and, worst of all from this perspective, the greening of cities legitimates the averaging of city and nature indiscriminately across the globe to the detriment of both. To think this in slightly different terms consider the following: what are natural resources when the natural is either commoditized or given gratuitously in prelimited lots within the urban fabric? 
One can imagine Wright's Broadacre City as the epitome and logical outcome of such a strategy, fig. 3 - a theoretical settlement in which both the 'city' and 'nature' disappear behind a veil of homogenised sub-urbanism.

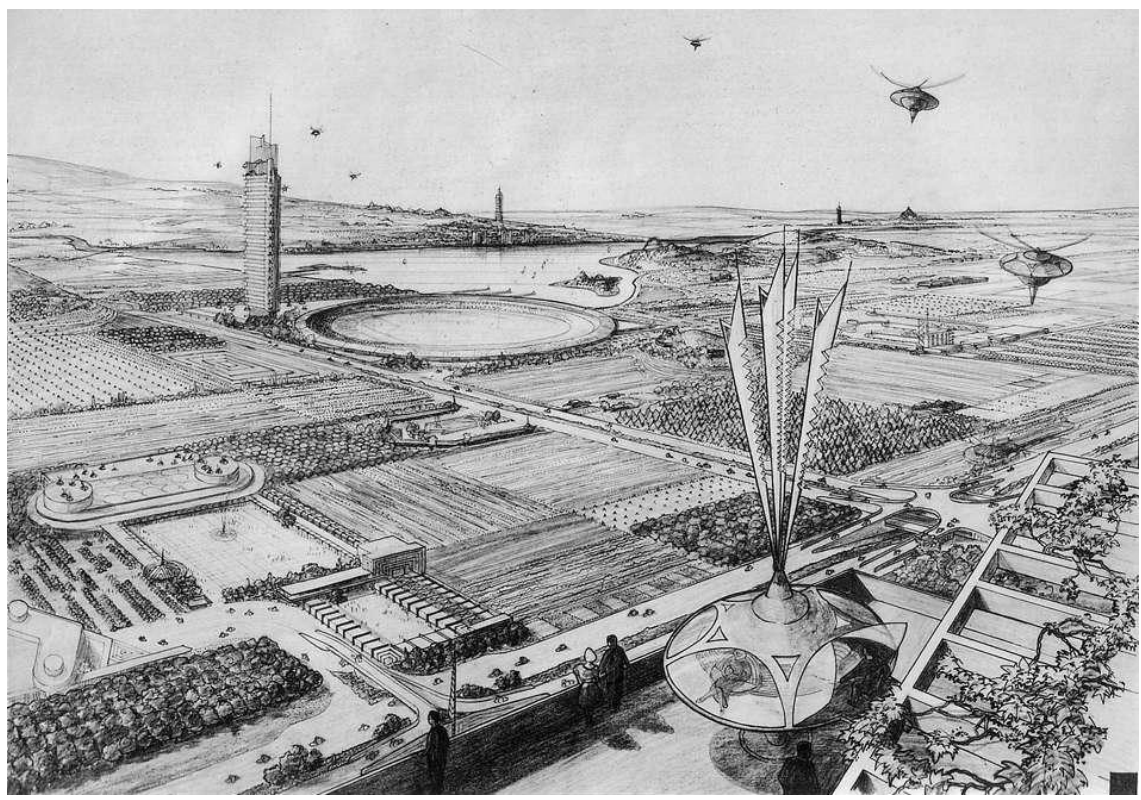

Figure 3: Wright's Broadacre City.

\subsection{The aim of perception}

"To perceive is to render oneself present to something through the body." Merleau-Ponty wrote this with the simplest encounter in mind: one person meeting an object in space [7]. Logically, the import and impact multiplies with each additional encounter. Cities, in this sense, are places of maximum potential perception. Nevertheless, Americans' fear of cities is often defended (especially by Americans' suffering this fear) on the grounds of congestion, on the overwhelming number of encounters that the city demands; and the virtue of small town or rural life, conversely, is predicated on the idea of limited but ostensibly more meaningful encounters. The chasm between these positions is important for what it hides.

To desire is not 'to have' but to want to have. What is it that people desire if it is other than perception via encounter? Arguably, nothing. Better stated, perhaps we only desire the satisfaction of desire itself; and the thing that most usefully serves as the object of this desire must be a thing easily obtained. There are few things more readily available, or more easily consumed, (particularly in the US) than the increasingly empty construct of nature. This is why we build city parks, suburban versions of Broadacre City, and the hamlets of New Urbanism: to satisfy desire and minimize experience. One does not have to imagine, dream, 
wait, travel or risk meeting too many different kinds of people; nature is right there, across the street.

Though an admittedly cynical view, I believe much is lost in easy satisfaction. Unfortunately, the horizontally dispersed city that an allegiance to reproduced nature requires does not offer the experiential resistance necessary for desire to occur. And the simulacrum is eventually seen as a poor substitute: one might legitimately ask, why live in a 'green' city when 'real' nature is only a few miles away? The technology of the technologically sustainable city is not enough of a lure to maintain the population. Arguably, the frequency and intensity of multiplying encounters found in a dense city, on the other hand, offer rewards in and of themselves that do not rely on an original that exists somewhere, out there.

\subsection{City of density/city of desire}

Commenting on Hegel's view of desire Judith Butler states, "Desire requires ... the transformation of the particularity of the natural world (the lived body as well as natural objects) into reflections of human activity; desire must become expressed through labour, for desire must give shape or form to the natural world in order to find itself reflected there...desire is always an effort to negate/transform the natural world [8]." There are multiple, entwined implications here. First, giving up the tendency to see manmade objects as diminutive or second- or third-rate forms of nature is a prerequisite for the creation of desire. Desire is worked for, laboured over; and it rewards only when it remains unsatisfied. Second, though less obvious, the construction of 'green cities', or nature-centric developments, inhibits the experience of desire by providing both nature and nature-transformed in a single perspective. As a result, there is no outside to desire. Instead of offering visions that are equal parts city and nature, architects and planners might create a more powerful and longerlasting lure by attempting to maximize the concept of the city, as not nature, as the place where nature is always conceptually present as the end of desire via its perceptual absence. If nature is the minimization of human density, and if nature is what many Americans most desire, perhaps a city of density might be the necessary trigger to a living city of desire.

\section{Conclusion}

Words and images, submission to fear, and a tacit belief in the primacy and ready accessibility of nature are all damning to the constitution of real sustainability. This term, sustainability, may very well mean the ability of some aspects of life to resist change. But the question remains: what are those aspects that we really want to maintain unchanged? The experience of desire is an easy answer insofar as it is one of the few experiences diminished (or destroyed) by fulfilment. Unfortunately, fear of cities greatly reduces opportunities for experiences of desire. The problem, furthermore, is cyclical. As Foucault argued, desire is not only experienced but it shapes experience as well [8]. Each 
experienced desire spurs the development of another; each sated desire gives way to comfort, contentment, and a general tendency to accept the status quo. Individuals, of course, are free to accept such a life; however, there is no workable conception of sustainability that can survive such indifference. The status quo is unsustainable. If we hope to define and eventually build truly sustainable developments, we must always desire better ways to keep the experience of desire alive.

\section{References}

[1] R. Burdett and D. Sudjic, (eds). The Endless City: the urban age project by the London School of Economics and Deutsche Bank's Alfred Herrhausen Society, Phaidon: New York, 2007.

[2] Y.F. Tuan, Landscapes of Fear, University of Minnesota Press: Minneapolis, pp. 145-174, 1979.

[3] E.O. Wilson, Consilience: the unity of knowledge, Vintage: New York, pp. 291-326, 1999.

[4] B. McKibben, Deep Economy: the wealth of communities and the durable future, Henry Holt \& company: New York, pp. 129-176, 2008.

[5] H. Lefebvre, The Urban Revolution, trans. R. Bononno, University of Minnesota Press: Minneapolis, pp. 185 and 27 respectively, 2003.

[6] D. Massey, for space, Sage: Thousand Oaks, pp. 97-98 and 130-142, 2006.

[7] M. Merleau-Ponty, The Primacy of Perception: and other essays on phenomenological psychology, the philosophy of art, history and politics, ed. J.M. Edie, Northwestern University Studies in Phenomenology and Existential Philosophy: Northwestern University Press, p. 42, 1964.

[8] J. Butler, Subjects of Desire: Hegelian reflections in twentieth-century France, Columbia University Press: New York, pp. 57 and 238, 1999. 